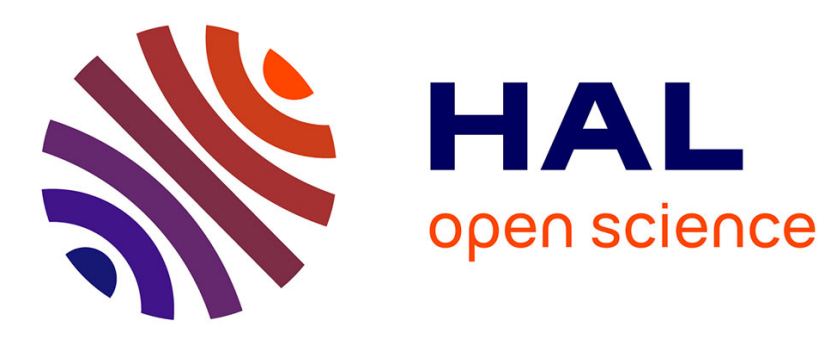

\title{
Recent advances in understanding inheritance of Holoprosencephaly
}

\author{
Christèle Dubourg, Artem Kim, Erwan Watrin, Marie de Tayrac, Sylvie
} Odent, Véronique David, Valérie Dupé

\section{- To cite this version:}

Christèle Dubourg, Artem Kim, Erwan Watrin, Marie de Tayrac, Sylvie Odent, et al.. Recent advances in understanding inheritance of Holoprosencephaly. American Journal of Medical Genetics Part C Seminar in Medical Genetics, 2018, Holoprosencephaly, 178 (2), pp.258-269. 10.1002/ajmg.c.31619 . hal-01812521v2

\section{HAL Id: hal-01812521}

\section{https://hal-univ-rennes1.archives-ouvertes.fr/hal-01812521v2}

Submitted on 14 Sep 2018

HAL is a multi-disciplinary open access archive for the deposit and dissemination of scientific research documents, whether they are published or not. The documents may come from teaching and research institutions in France or abroad, or from public or private research centers.
L'archive ouverte pluridisciplinaire $\mathbf{H A L}$, est destinée au dépôt et à la diffusion de documents scientifiques de niveau recherche, publiés ou non, émanant des établissements d'enseignement et de recherche français ou étrangers, des laboratoires publics ou privés. 


\title{
Recent advances in understanding inheritance
}

\section{of Holoprosencephaly}

\author{
Christèle Dubourg ${ }^{1,2}$, Artem Kim ${ }^{1}$, Erwan Watrin ${ }^{1}$, Marie de Tayrac ${ }^{1,2}$, Sylvie Odent ${ }^{1,3}$, \\ Véronique David*1,2, Valérie Dupé ${ }^{1}$.
}

1 - Univ Rennes, CNRS, IGDR (Institut de génétique et développement de Rennes) - UMR 6290, F - 35000

Rennes, France

2 - Service de Génétique Moléculaire et Génomique, $\mathrm{CHU}$, Rennes, France.

3 - Service de Génétique Clinique, CHU, Rennes, France.

* to whom correspondence should be addressed

veronique.david@univ-rennes1.fr

Christèle Dubourg, Pharm.D, PhD, is a molecular geneticist, with a specific interest in the field of developmental anomalies (intellectual deficiency, holoprosencephaly), and in charge of molecular diagnoses of these diseases in the Laboratory of Molecular Genetics and Genomics at the University Hospital of Rennes.

Artem Kim is a data scientist specialized in clinical NGS data analysis. He is currently working toward his PhD, which focuses on genetic basis of holoprosencephaly.

Erwan Watrin holds a PhD in Biological Sciences and is principal investigator at the French CNRS (Centre National de la Recherche Scientifique). His work focuses on chromosome biology and its relevance to developmental disorders with a particular interest for cohesinopathies.

Marie de Tayrac, PhD, is head of the Laboratory of Bioinformatics and Computational Genetics at the University Hospital of Rennes. Her research activities at the Institute of Genetics and Development of Rennes focus on deciphering the genetic basis of human diseases using bioinformatics and systems biology approaches.

Sylvie Odent, MD, PhD is a Clinical Geneticist, head of the department and is responsible for the teaching of genetics at the Faculty of Medicine of Rennes. Her research projects focus on neurodevelopmental syndromes, with a special interest in brain malformations (Holoprosencephaly) and rare diseases of development. She coordinates an accredited center of expertise in the west of France (CLAD-Ouest) and is a member of the European Reference Network ITHACA.

Véronique David, Pharm PhD, is head of the Laboratory of Molecular Genetics and Genomics at the University Hospital of Rennes. She is also head of the research team "Genetics of pathologies related to development " at the Institute of Genetics and Development of Rennes, aiming at studying the genetics and physiopathology of complex developmental diseases. 
Valérie Dupé, PhD, is a research scientist at Inserm (Institut national de la santé et de la recherche médicale). After having acquired a strong background in vertebrate development at the IGBMC (Strasbourg, France) and UCL (London), she has joined the Institute of Genetics and Development of Rennes (IGDR) to study brain development with a special interest in Holoprosencephaly.

\begin{abstract}
Holoprosencephaly (HPE) is a complex genetic disorder of the developing forebrain characterized by high phenotypic and genetic heterogeneity. HPE was initially defined as an autosomal dominant disease, but recent research has shown that its mode of transmission is more complex. The past decade has witnessed rapid development of novel genetic technologies and significant progresses in clinical studies of HPE. In this review, we recapitulate genetic epidemiological studies of the largest European HPE cohort and summarize the novel genetic discoveries of HPE based on recently developed diagnostic methods. Our main purpose is to present different inheritance patterns that exist for HPE with a particular emphasis on oligogenic inheritance and its implications in genetic counseling.
\end{abstract}

\title{
INTRODUCTION
}

Holoprosencephaly is a severe developmental disorder classically defined as incomplete cleavage of the forebrain that originates from failed midline delineation during early development. There are several degrees of severity defined by the extent of the brain malformations. For the most severe cases, malformations are divided into alobar, semilobar or lobar forms. These brain abnormalities are associated with facial anomalies that are also of varying severity ranging from cyclopia to milder signs such as ocular hypotelorism. The full spectrum of HPE also includes microforms characterized by facial midline defects (e.g., single median incisor) without brain malformations typical of HPE (Cohen, 2006; Dubourg et al., 2007; Hahn, Barnes, Clegg, \& Stashinko, 2010; Muenke \& Beachy, 2000).

HPE occurs in most ethnic groups worldwide. Although implication of maternal diabetes in HPE has been reported (Barr et al., 1983), the well-established origin of HPE remains almost exclusively genetic and consists of chromosomal abnormalities and nucleotide-based variants (Dubourg et al., 2007, 2016; Solomon et al., 2012). So far, 17 genes have been implicated in HPE, all of which encode 
proteins belonging to brain development pathways. Sonic Hedgehog $(S H H)$ was the first discovered HPE gene (Roessler et al., 1996) and its alterations remain the most common cause of nonchromosomal HPE (Dubourg et al., 2016). SHH has been extensively studied and its functions during early brain development are now well described. A morphogenetic gradient of SHH is established from the ventral midline of the diencephalon to induce appropriate cleavage of both forebrain and eyefield. Remarkably, all HPE genes described so far are involved in the regulation of SHH activity (Sun et al., 2014; Xavier et al., 2016).

Initially described as an autosomal dominant trait with incomplete penetrance and variable expressivity, the mode of inheritance of HPE has been progressively redefined. The apparent autosomal dominant transmission with incomplete penetrance observed in a few HPE families may well be due to the cumulative effects of rare variants in two genes or more. Undeniably, the prevalence of oligogenicity has increased for several developmental pathologies since Next Generation Sequencing (NGS) technologies became accessible (Bamshad et al., 2011). Despite technical advances, defining the causative gene for HPE remains a difficult task, and even when one underlying variant is known, prenatal prediction remains uncertain.

Here, we describe clinical features and inheritance aspects of this disease with examples from our experience.

\section{Clinical and genetics features of the cohort}

\section{The European HPE cohort}

In 1996, a European HPE network was established in Rennes, France. Patients are recruited by clinicians from the different French centers of reference for rare developmental diseases as well as from several European clinical centers in the UK, Belgium, Italy, Spain and Portugal. Half of collected samples were fetuses, which enriched our cohort for severe HPE phenotypes (Mercier et al., 2011). Over the years, we have collected over 2,700 blood DNA samples or frozen fetal tissues, including patients and relatives, and gathered clinical data and DNA for 1,420 HPE probands. Our cohort contains both apparently sporadic and familial cases, excluding those associated with other malformation syndromes or with known chromosomal abnormalities that could be revealed by standard cytogenetic analysis (e.g., trisomies 18 and 13).

HPE presents a wide continuous spectrum of clinical malformations ranging from severe to milder forms. Our cohort is representative of the full clinical spectrum of HPE phenotypes (Mercier et al., 
2011). Within this cohort, the most severe brain malformations are categorized into alobar, semilobar or lobar form. Middle interhemispheric fissure (syntelencephaly) - incomplete separation of the posterior frontal and parietal regions - also belongs to the HPE spectrum (Figure 1). These brain abnormalities are significantly correlated with a variety of distinct facial anomalies ranging from cyclopia, the most severe form, to milder signs such as ocular hypotelorism. Severe facial phenotypes, such as cyclopia, ethmocephaly (proboscis) and cebocephaly are more highly associated with alobar HPE. Similarly, premaxillary agenesis, cleft lip or palate and milder ocular abnormalities (coloboma, retinal dysplasia) are mostly associated with semilobar HPE while the mild midface malformations, such as pyriform sinus stenosis and choanal stenosis are mostly found in lobar HPE. Patients who present the mildest facial abnormalities, such as hypotelorism, cleft lip or single median incisor, generally do not present easily detectable brain malformations (Mercier et al., 2011). These HPE microforms can nonetheless be associated with microcephaly and intellectual disability and their molecular diagnosis is therefore important for proper patient care (Bruel et al., 2017; Solomon et al., 2010). Notably, most of these microforms have been diagnosed only because they were relatives of patients with severe HPE. Some families manifest a wide range of phenotypes, from typical alobar HPE with perinatal lethality to microforms such as microcephaly, hypotelorism or both (Mercier et al., 2011). These different observations and clinical correlations made on a European cohort can be extended to all HPE cohorts, as they are very similar to those of North American patients (Lacbawan et al., 2009; Solomon et al., 2010).

As the frequency of microform HPE is underestimated, we are currently expanding our diagnostic approach to mildly affected relatives of a classical HPE patient. When a typical HPE patient is diagnosed in a family, we routinely perform a careful examination of all family members including neuroimaging techniques (MRI) and determination of clinical features that are not traditionally considered as a part of the HPE spectrum. Our goal is to expand our cohort to a larger number of HPE microforms to ensure that we cover the entire HPE spectrum.

\section{The evolution of genetic strategies for HPE diagnosis}

\section{Sanger sequencing and detection of microdeletions in the major HPE genes}

From the discovery of the first genes responsible for HPE until recently, genetic analysis of HPE patients has mainly relied on a Sanger sequencing approach (Mercier et al., 2011). During that period (1997 to 2010), screening our cohort for nucleotide-based variants in the four HPE genes - SHH, Zinc Finger Protein 2 (ZIC2), Six Homeobox 3 (SIX3) and the Homeobox protein TGIF1 - provided a global variant detection rate of $20 \%$ (8.2 \% for SHH, $7.4 \%$ for ZIC2, $3.9 \%$ for SIX3 and $1.1 \%$ for TGIF1 (Mercier et al., 2011). All variants in these genes were detected heterozygously, and were shown to be loss-of-function variants (Roessler, El-Jaick, et al., 2009; Roessler, Lacbawan, et al., 2009). These 
genes have constituted the four major genes of HPE. Meanwhile, novel genes have been implicated in sporadic cases of HPE (Table II and Roessler, El-Jaick, et al., 2009). The implication of each gene represents less than $1 \%$ of HPE patients and they are therefore referred to as minor genes.

In 2003, variants in GLI2, one crucial effector of SHH signaling pathway (Ruiz i Altaba, Palma, \& Dahmane, 2002), had been described in HPE patients (Roessler et al., 2003), and screening of our cohort (Figure 1) revealed GLI2 variants in $3.2 \%$ of the 302 patients tested (Mercier et al., 2011), thus placing GLI2 as a major gene.

Identification of variants combined with detailed clinical assessment of HPE patients has allowed establishing some genotype-phenotype correlations (Mercier et al., 2011; Solomon et al., 2010). The most severe types of HPE (alobar and semilobar) tend to be associated with ZIC2 and SIX3 alterations while $S H H$ tends to be more frequently associated with microforms. Remarkably, in SHH and SIX3 cases, the facial dysmorphism is associated with brain anomalies while the probands of the ZIC2 group tend to have a combination of severe HPE with few of the facial features. GLI2 variants were preferentially found in patients presenting HPE microforms together with secondary specific features such as pituitary anomalies (Bear et al., 2014). These genotype-phenotype correlations have contributed to facilitate molecular analysis and genetic counseling for HPE.

Initially, Sanger sequencing has successfully allowed establishing molecular diagnoses for about $20 \%$ of HPE patients present in our cohort (Mercier et al., 2011). In order to explain, at least part of the remaining $80 \%$ of unsolved cases, we have searched for microdeletions in the major HPE genes (SHH, ZIC2, SIX3 and TGIF1) first by quantitative multiplex PCR of short fluorescent fragments (QMPSF) and then by multiplex ligation-dependent probe amplification (MLPA). Deletions in HPE genes were thereby shown to be a common cause of HPE in up to $8.5 \%$ of fetuses and in $5 \%$ in our whole cohort (Bendavid et al., 2006).

In 2006, the combination of these different approaches allowed us to diagnose molecularly $25 \%$ of our patients, very similar to the success rate of our American colleagues (Roessler, El-Jaick, et al., 2009; Solomon et al., 2010, 2012). As $75 \%$ of cases remained unsolved, we and others in the field have considered alternative genetic causes of HPE.

\section{Chromosomal abnormalities and copy number variants in HPE}

Since 2006, a pangenomic technique named comparative genomic hybridization (CGH) array has been used to screen the entire genome for copy number variations (CNVs). The first study we carried out during 2006-2009 revealed an impressively high rate of chromosomal rearrangements in HPE patients (22\%), of which $14 \%$ occurred de novo and $8 \%$ were inherited (Bendavid et al., 2009, 2010). Furthermore, the observation of these CNVs can also lead to the detection of parental-balanced 
translocations and can subsequently improve prenatal diagnosis in such families.

In addition, these CNVs involved novel potential HPE loci. Despite relatively low recurrence rates of CNVs, overlapping 6qter region deletions among 4 unrelated patients allowed identification of a ligand of the NOTCH signaling pathway, Delta-like 1 (DLL1) as candidate gene (Dupé et al., 2011). Subsequent detection of a nucleotide-based variant in a distinct patient provided further evidence for DLL1 as HPE gene, and, together with expression and functional studies in vertebrates (Ratié et al., 2013; Ware, Hamdi-Rozé, \& Dupé, 2014), allowed defining Notch as a novel signaling pathway involved in HPE.

In addition, microrearrangements found in unique cases, pointed to candidate genes such as SIX6 and OTX2, which are both implicated in early brain development (Jean, Bernier, \& Gruss, 1999; Jin, Harpal, Ang, \& Rossant, 2001). Another study using a similar approach has also highlighted OTX2 as a candidate gene (Rosenfeld et al., 2010).

Since this work, CGH-array has been and still is part of our systematic molecular screening of HPE patients. The novel detected CNVs are listed in Table II. The proportion of CNVs observed in this second period (2010-2017) is reduced as compared to that of our previous study (Bendavid et al., 2009). The rate of disease-relevant CNVs is now shown to be $10 \%$, half of which being de novo. Several of these rearrangements are recurrently observed in cases of intellectual disability, such as 2.6 Mb-microdeletion of 22q11.21 (proximal deletion) corresponding to DiGeorge syndrome (Burnside, 2015), 16p11.2 microduplication that confers susceptibility to autism (Fernandez et al., 2010), 16p13.11 encompassing the NDE1 gene involved in brain neurogenesis and rhombencephalosynapsis (Bakircioglu et al., 2011; Démurger et al., 2013) and 15q11.2 microdeletion emerging as one of the most common cytogenetic abnormalities in intellectual disability and autism spectrum disorder (Butler, 2017). These deletions and duplications are thus at the origin of other neurodevelopmental disorders but are not sufficient to fully explain HPE. Nevertheless, CNV detection has increased the diagnostic yield from $25 \%$ to $35 \%$ in our cohort.

\section{Next-generation sequencing (NGS) methods and their use for HPE diagnosis}

The discovery of SHH in 1996 was followed by that of other genes - ZIC2, SIX3, TGIF1 and GLI2. Since then, subsequent studies of the pathways implicating these major genes have contributed to the identification of additional HPE genes (Table I). Variants in genes involved in the SHH signaling pathway - PTCH1, DISP1, CDON, GAS1, BOC and SUFU - were described in some HPE patients (Bae et al., 2011; Dubourg et al., 2016; M. Hong et al., 2017; Ming et al., 2002; Pineda-Alvarez et al., 2012; Roessler, Ma, et al., 2009). A few variants have been described in NODAL, TDGF1, FOXH1, which encode proteins belonging to the Nodal/TGF-beta pathway (de la Cruz et al., 2002; Roessler et al., 2008; Roessler, Pei, et al., 2009). The Fibroblast Growth Factor pathway has also been implicated in 
HPE through variants in FGF8 and its receptor FGFR1 (Arauz et al., 2010; Simonis et al., 2013). More recently, variants in STIL, a gene implicated in the formation of the primary cilia, were also described in HPE families (Kakar et al., 2015; Mouden et al., 2015). These are minor genes as they are reported in less than $1 \%$ of HPE cases. Importantly, all these genes have in common the ability to affect SHH activity (Sun et al., 2014; Xavier et al., 2016).

Taking advantage of next-generation sequencing (NGS) in 2010, we established the first gene-panel sequencing method that targeted all known HPE genes (Dubourg et al., 2016). At the time we are writing this manuscript, more than 300 HPE patients have been tested. This study revealed that $\mathrm{SHH}$, ZIC2, SIX3 and GLI2 retain their position of major genes and TGIF1 is relegated to the minor gene group. Furthermore, the identification of numerous variants in FGF8 and FGFR1 strengthens the involvement of FGF signaling in HPE (Figure 1B). Recent functional analysis in Zebrafish has confirmed the contribution of FGF8 variants in HPE (Hong et al., 2016; Hong, Hu, Roessler, Hu, \& Muenke, 2018) in accordance with the known function of FGF signaling during the specification of the dorso-ventral axis of the forebrain (Storm et al., 2006).

From the results we obtained over the years from our 1,420 probands, the 10 first-ranked genes involved are SHH (5.4\%), ZIC2 (5.2\%), GLI2 (3.2\%), SIX3 (3.0\%), FGF8 (2.5\%), FGFR1 (2.0\%), DISP1 (1.2\%), DLL1 (1.2\%) and TGIF1 (0.9\%) (Figure 2; Table I). Some rare deleterious variants have been found in SUFU, a regulator of the Sonic-hedgehog-signaling pathway (Dubourg et al., 2016). By contrast, we did not detect any pathogenic variants in the following minor genes: PTCH1, NODAL, GAS1, TDGF1, CDON, and FOXH1. To date, only a small number of variants have been reported for these genes (Bae et al., 2011; de la Cruz et al., 2002; Ming et al., 2002; Roessler et al., 2008; Roessler, Pei, et al., 2009). Therefore, more data need to be collected to unambiguously assign these genes to HPE etiology.

As NGS technology evolved and became more accessible, whole exome sequencing (WES) is now routinely used to investigate novel HPE patients (see paragraph below). We expect this new approach will allow us not only to increase the diagnostic yield but also to identify novel HPE genes. Along the same lines, we are now establishing whole genome sequencing (WGS) approach in order to identify other alterations located in the noncoding part of the genome ( $98 \%)$ that has remained largely unexplored until now in the context of HPE.

An important observation has emerged from our experience as clinical reference center for HPE. When comparing the percentage of positive diagnoses between 2010 and 2017 it appears surprisingly stable (about $35 \%$ ), despite the fact that sequencing technology has improved and that 
the number of HPE genes has increased. A closer examination of our data indicates that the fraction of patients with a CNV or with a variant in one of the major genes $(S H H, Z I C 2$ and SIX3) has been reduced by half as compared to that of 2010. Paradoxically, this reduction of cases is due to the increase of knowledge in diagnosis of HPE. Indeed, more and more clinical genetic centers are now able to perform their own molecular diagnoses for HPE. When a deleterious variant is found in one of the major HPE genes or when there is a CNV, the patient is not systematically referred to the reference center (i.e., Rennes, France) anymore. In contrast, when a molecular diagnosis could not be established, the patient data are sent to us for further investigation. As a consequence, the proportion of cases with an alteration in the major HPE genes has decreased in our cohort, which explains why our success rate of molecular diagnosis has remained stable over the years.

\section{Modes of inheritance in HPE}

In 1996, we initiated an epidemiologic study on 258 HPE cases and concluded that for non-syndromic and non-chromosomal HPE, the most compatible mode of transmission was autosomal dominant with incomplete penetrance and a variable expressivity (Odent, Le Marec, Munnich, Le Merrer, \& Bonaïti-Pellié, 1998).

In HPE, the analysis of the first four major genes revealed that in most of the cases (70\% for $\mathrm{SHH}$ and $S I X 3)$ the variants were inherited from a parent who was asymptomatic or only mildly affected (microform HPE). By classic textbook definitions, autosomal dominant inheritance is defined as the transmission of disease from an affected parent to an affected offspring. In this model, half of this parent's offspring is expected to be affected. Our observations show that this model (and ratios of affected offspring) does not appear to apply to HPE. Furthermore, although as many as 17 genes have been linked to HPE, variants in these genes collectively explain only $25 \%$ of all HPE cases. It suggests that HPE is a complex disease with an increasing number of causative genes for which inheritance can vary depending of the affected gene as well as other related factors. This observation stresses the need for clarifying potential modes of its inheritance. In this section, we present different cases from our cohort and discuss their corresponding inheritance pattern.

\section{De novo versus inherited variants in HPE}

Systematic sequencing of the major HPE genes has shown a high proportion of de novo variants in ZIC2 (70 \%), SHH (30\%) and SIX3 (30\%) (Figure 3 and Mercier et al., 2011). Thus, de novo variants are implicated in numerous sporadic HPE cases. In accordance with the essential role of these genes in early brain development, these de novo variants are loss-of-function and tend to be more deleterious than inherited ones (Roessler, El-Jaick, et al., 2009). 
In our cohort, $50 \%$ of FGFR1 variants appeared de novo. Adding to complexity, FGFR1 is prone to mosaïcism as we could show in one family in which a patient's father presents an attenuated HPE phenotype (Dubourg et al., 2016). Interestingly, cases of mosaïcism involving FGFR1 were described in other diseases like Hartsfield syndrome and encephalocraniocutaneous lipomatosis (Bennett et al., 2016; Dhamija et al., 2014). It should be noted that mosaic variants could be overlooked depending on the type of tissue tested and on the detection method (Braunholz et al., 2015), which could artificially increase the proportion of de novo variants.

\section{Rare examples of autosomal recessive inheritance in HPE patients}

In 2007, first case of recessive inheritance was described, involving two compound heterozygous variants in TGIF1 (El-Jaick et al., 2007). Then, homozygous variant in FGF8 was identified in one consanguineous HPE family (McCabe et al., 2011). More recently, another case of recessive inheritance involving FGF8 was described (Hong et al., 2018). This FGF8 variant was functionally validated and shown to be hypomorph, which is consistent with the indispensable role of FGF8 during early development (Sun, Meyers, Lewandoski, \& Martin, 1999). A severe loss of function is probably not compatible with embryonic development.

Still, consanguineous families should predispose descendants to autosomal recessive gene combinations. Homozygosity mapping performed on 8 consanguineous HPE families from our cohort did not initially reveal any homozygous variants. Only by complementing mapping with WES we were able to detect in one of these families a homozygous hypomorphic variant for the gene STIL (Mouden et al., 2015). A homozygous nonsense variant of STIL was independently reported by others (Kakar et al., 2015). STIL is localized to centrioles where it participates in SHH signaling through its function in primary cilia biology and is known to be involved in microcephaly (David et al., 2014). Notably, in these two families, HPE is transmitted as a recessive trait associated with severe microcephaly. As no additional variant of STIL was described on more than 100 HPE patients tested (Karkera et al., 2002; Mouden et al., 2015), STIL gene therefore belongs to the minor HPE genes.

We also described a female HPE patient displaying two different mutated DISP1 alleles both inherited from her two healthy parents (Mouden et al., 2016). These missense variants in the exon 10 were predicted to be deleterious. DISP1 is a protein that mediates the secretion of $\mathrm{SHH}$, that is required for long-range cell to cell signaling (Tian, Jeong, Harfe, Tabin, \& McMahon, 2005). This patient presents a localized fusion of forebrain hemispheres (mild form of HPE). We believe that hypomorphic effect of DISP1 missense variant impacts SHH secretion to such an extent that global SHH signaling is decreased to pathological level.

All cases of autosomal recessive inheritance reported so far involve unaffected parents and concern minor HPE genes (Figure 3). Despite systematic sequencing of the major genes (SHH, ZIC2 and SIX3) 
in our 1420 probands and others (Roessler, Vélez, Zhou, \& Muenke, 2012), no recessive case has been reported for these genes. It suggests that homozygous variants in major genes are not compatible with embryonic development, which is fully consistent with their crucial roles during early developmental stages (Geng \& Oliver, 2009; Schachter \& Krauss, 2008) and may explain why recessive inheritance is rare in HPE.

\section{Oligogenic inheritance}

As presented above, variants in HPE genes are frequently inherited from a parent without a typical HPE phenotype (Mercier et al., 2011). Within a given family we observed a large phenotypic heterogeneity between the different variant carriers, illustrating the incomplete expressivity of these variants (Kruszka, Hart, Hadley, Muenke, \& Habal, 2015; Mercier et al., 2011; Solomon et al., 2010; Stokes et al., 2018). These observations support the hypothesis that in these families variant in one HPE-related gene is necessary but not sufficient for the disease to occur, which implies more variants are required for complete phenotypic spectrum. This oligogenic mode of inheritance has already been proposed by our colleagues, who referred to it as "automosal dominant with modifier effects" (S. Hong et al., 2016; M. Hong et al., 2017). In this oligogenic model, penetrance and expressivity of existing heterozygous variant is modulated by variants in other genes associated with HPE. Such a synergistic effect between distinct deleterious genetic events is now well-documented in several other hereditary developmental diseases (e.g, Alport, Bardet-Biedl and Kallman Syndromes) (Maione et al., 2018; Mencarelli et al., 2015; M’hamdi et al., 2014). In a similar manner, HPE could result from cumulated effects of distinct variants (Mercier, 2013). The use of animal models has reinforced this possibility. Numerous examples of double heterozygous mutant mice displaying HPE-like phenotypes provided evidence for oligogenism by implicating genes controlling either the same or distinct signaling pathways (Krauss, 2007).

For years, when a patient presented a deleterious variant in HPE gene, the analysis was interrupted because a likely genetic cause for the disease had been felt to be found. We believe it explains why rare HPE cases compatible with oligogenism have been reported so far (Ming \& Muenke, 2002).

High-throughput sequencing and genomic technologies provided a unique opportunity to address this oligogenic inheritance in HPE. Thanks to WES, we have recently started to address the presence of additional events in HPE patients with a known variant in a HPE gene. Some of our most recent unpublished results on the subject are presented below.

\section{Examples of digenic inheritance in HPE}


Digenic inheritance is the simplest form of inheritance for genetically complex diseases. Systematic sequencing of major HPE genes, have described isolated cases with variants in two genes (e.g., SHH/ZIC2; SHH/TGIF) (Ming \& Muenke, 2002). We also reported several cases of chromosomal rearrangement (CNV) associated with variant in HPE-related gene (Mercier et al., 2011).

In one family, presented in figure $2 \mathrm{~A}$, deleterious variants in both $S H H$ and DISP1 co-segregated with the disease, while relatives carrying variant only in either SHH or DISP1 presented a mild or no disease phenotype (Mouden et al., 2016). This first digenic case in a family with several HPE patients prompted us to consider and further investigate digenic inheritance in families with HPE. This hypothesis was significantly reinforced by our experience with HPE genes routinely analyzed by targeted NGS. This study revealed that out of 257 HPE probands, $16 \%$ of the variants used for diagnosis were found in association with a second variant (e.g., FGF8/FGFR1, FGF8/DLL1, DLL1/SHH, DISP1/SUFU) (Dubourg et al, 2016). More recently, two more cases of digenism were reported (ZIC2/BOC and TGIF/BOC) in HPE patients (Hong et al., 2017). Considering the systematic use of NGS on HPE patients and the increasing number of HPE genes, we expect that digenic cases will continue to accumulate further.

\section{Cases of oligogenic inheritance in HPE}

The increasing number of digenic cases provides novel insights into genetic etiology of HPE such as oligogenic inheritance. Oligogenic pattern has never been described in HPE, but is often suggested in other complex diseases such as ciliopathies (Reiter \& Leroux, 2017), retinitis pigmentosa (Ali, Rahman, Cao, \& Yuan, 2017), autism spectrum disorder (ASD) (Yin \& Schaaf, 2017), amyotrophic lateral sclerosis (ALS) (Nguyen, Van Broeckhoven, \& van der Zee, 2018), or porphyria (Lenglet et al., 2018). These disorders share with HPE high genetic and phenotypic heterogeneity as well as incomplete penetrance. We therefore considered oligogenic inheritance as a likely cause of HPE that may account for at least a substantial part of enigmatic cases.

With constantly evolving knowledge of disease genes and emergence of new analysis methods, it has become important to us to reanalyze systematically previous unsolved cases. In that aim, we reevaluated unsolved HPE families by taking into account the possibility of oligogenic inheritance. The study included families with no identified causal variant as well as families with variants in $\mathrm{SHH}$, ZIC2, SIX3 or TGIF1 inherited from clinically unaffected/mildly affected parent. Parts of this unpublished work are presented and discussed hereafter.

We combined trio-based whole exome sequencing with deep clinical phenotyping of the patients. Variant analysis was further improved by a gene prioritization approach based on clinical ontologies and co-expression networks of known disease-related signaling pathways. 
In one family, presented in Figure $2 \mathrm{~B}$, we identified a variant in $\mathrm{SH}$, which was inherited from the mother presenting with hypotelorism. Considering oligogenic inheritance, we addressed whether paternal variants could contribute to HPE phenotype in combination with the SHH variant inherited from the mother. Indeed, our analysis revealed paternally inherited variants in two candidate HPE genes - FAT1 and NDST1. Both variants were rare (minor allele frequency below $1 \%$ ) and were predicted deleterious by the majority of bioinformatics algorithms (CADD score > 20). FAT1 is a protocadherin and its knockdown in mouse causes severe midline defects including HPE (Ciani, Patel, Allen, \& ffrench-Constant, 2003) and NDST1 is an N-deacetylase sulfotransferase and the corresponding mice mutants exhibit reduced SHH signaling and HPE-like phenotype (Grobe, 2005). Additionally, clinical phenotyping and analysis of cross-species similarities provided further evidence of causality for these genes by revealing a strong overlap of clinical features between the patient and the FAT1 (proboscis) and NDST1 (eye defects) mutant mice. Finally, the segregation analysis showed that the combination of variants in SHH/FAT1/NDST1 was exclusively found in the two affected individuals of this family (Figure 2B). This example nicely illustrates oligogenic inheritance in HPE where the disease results from accumulation of multiple variants in genes associated to HPE phenotypes and/or implicated in $\mathrm{SHH}$ signaling (Figure 3). We therefore pursue a systematic reevaluation of all unsolved HPE cases. We believe that numerous other genes will be characterized in patients with oligogenism transmission. An exciting future challenge will be to test experimentally the combined effect of these different variants on early brain development.

\section{Our clinical approach}

Over the last two decades, we have followed for prenatal diagnosis 26 HPE families affected by a first case of severe HPE carrying a variant in one of the major HPE gene. In 18 instances, we were able to reassure the parents after establishing the absence of the gene alteration in the fetus. Fetal MRI scan was normal later in pregnancy, and no child had medical problems after birth. A genetic alteration (in SHH, SIX3 or TGIF1) was found in the 8 other cases: 5 children were born, either without brain malformation and asymptomatic, or presenting a less severe form than the proband as predicted by the fetal brain surveillance. Three pregnancies were interrupted after MRI scans showed HPE features.

Nowadays, even when a causative gene for HPE has been found in a patient, the molecular diagnosis is probably not fully established. In order to properly address the molecular diagnosis, it will be necessary to compare the detailed phenotypes of the different family members with the segregation of relevant rare variants. For practitioners involved in counseling, an important consideration is how to communicate results of genetic analysis when potentially deleterious variants are identified but 
not yet functionally validated. Ideally, determining the contribution of each variant to the phenotype would be a condition for reliable genetic counseling in HPE families with oligogenic transmission.

\section{Conclusion}

In this review, we aimed to present the different patterns of inheritance of HPE in the light of our experience (Figure 3). In some cases, the disease is due to de novo variants; in rare cases the disease exhibits classical Mendelian inheritance with autosomal recessive transmission. In most cases, it emerges that the penetrance and the phenotypic variability have digenic or oligogenic origin. This complex genetic architecture will be better understood by analysis of hundreds of genes with NGS techniques on unsolved HPE cases. Our future challenge will be to differentiate rare variants that have significant impact on the observed phenotype from those with no effect. 


\section{References}

Ali, M. U., Rahman, M. S. U., Cao, J., \& Yuan, P. X. (2017). Genetic characterization and disease mechanism of retinitis pigmentosa; current scenario. 3 Biotech, 7(4), 251.

https://doi.org/10.1007/s13205-017-0878-3

Arauz, R. F., Solomon, B. D., Pineda-Alvarez, D. E., Gropman, A. L., Parsons, J. A., Roessler, E., \& Muenke, M. (2010). A Hypomorphic Allele in the FGF8 Gene Contributes to Holoprosencephaly and Is Allelic to Gonadotropin-Releasing Hormone Deficiency in Humans. Molecular Syndromology, 1(2), 59-66. https://doi.org/10.1159/000302285

Bae, G.-U., Domené, S., Roessler, E., Schachter, K., Kang, J.-S., Muenke, M., \& Krauss, R. S. (2011). Mutations in CDON, encoding a hedgehog receptor, result in holoprosencephaly and defective interactions with other hedgehog receptors. American Journal of Human Genetics, 89(2), 231-240. https://doi.org/10.1016/j.ajhg.2011.07.001

Bakircioglu, M., Carvalho, O. P., Khurshid, M., Cox, J. J., Tuysuz, B., Barak, T., ... Woods, C. G. (2011). The essential role of centrosomal NDE1 in human cerebral cortex neurogenesis. American Journal of Human Genetics, 88(5), 523-535. https://doi.org/10.1016/j.ajhg.2011.03.019

Bamshad, M. J., Ng, S. B., Bigham, A. W., Tabor, H. K., Emond, M. J., Nickerson, D. A., \& Shendure, J. (2011). Exome sequencing as a tool for Mendelian disease gene discovery. Nature Reviews. Genetics, 12(11), 745-755. https://doi.org/10.1038/nrg3031

Barr, M., Hanson, J. W., Currey, K., Sharp, S., Toriello, H., Schmickel, R. D., \& Wilson, G. N. (1983). Holoprosencephaly in infants of diabetic mothers. The Journal of Pediatrics, 102(4), 565-568.

Bear, K. A., Solomon, B. D., Antonini, S., Arnhold, I. J. P., França, M. M., Gerkes, E. H., ... Muenke, M. (2014). Pathogenic mutations in GLI2 cause a specific phenotype that is distinct from holoprosencephaly. Journal of Medical Genetics, 51(6), 413-418. https://doi.org/10.1136/jmedgenet2013-102249

Bendavid, C., Dubourg, C., Gicquel, I., Pasquier, L., Saugier-Veber, P., Durou, M.-R., ... David, V. (2006). Molecular evaluation of foetuses with holoprosencephaly shows high incidence of microdeletions in the HPE genes. Human Genetics, 119(1-2), 1-8. https://doi.org/10.1007/s00439005-0097-6

Bendavid, C., Dupé, V., Rochard, L., Gicquel, I., Dubourg, C., \& David, V. (2010). Holoprosencephaly: An update on cytogenetic abnormalities. American Journal of Medical Genetics. Part C, Seminars in Medical Genetics, 154C(1), 86-92. https://doi.org/10.1002/ajmg.c.30250

Bendavid, C., Rochard, L., Dubourg, C., Seguin, J., Gicquel, I., Pasquier, L., ... David, V. (2009). Array-CGH analysis indicates a high prevalence of genomic rearrangements in holoprosencephaly: an updated map of candidate loci. Human Mutation, 30(8), 1175-1182.

https://doi.org/10.1002/humu.21016

Bennett, J. T., Tan, T. Y., Alcantara, D., Tétrault, M., Timms, A. E., Jensen, D., ... McDonell, L. M. (2016). Mosaic Activating Mutations in FGFR1 Cause Encephalocraniocutaneous Lipomatosis. American Journal of Human Genetics, 98(3), 579-587. https://doi.org/10.1016/j.ajhg.2016.02.006

Braunholz, D., Obieglo, C., Parenti, I., Pozojevic, J., Eckhold, J., Reiz, B., .. Kaiser, F. J. (2015). 
Hidden mutations in Cornelia de Lange syndrome limitations of sanger sequencing in molecular diagnostics. Human Mutation, 36(1), 26-29. https://doi.org/10.1002/humu.22685

Bruel, A.-L., Franco, B., Duffourd, Y., Thevenon, J., Jego, L., Lopez, E., ... Thauvin-Robinet, C. (2017). Fifteen years of research on oral-facial-digital syndromes: from 1 to 16 causal genes. Journal of Medical Genetics, 54(6), 371-380. https://doi.org/10.1136/jmedgenet-2016-104436

Burnside, R. D. (2015). 22q11.21 Deletion Syndromes: A Review of Proximal, Central, and Distal Deletions and Their Associated Features. Cytogenetic and Genome Research, 146(2), 89-99. https://doi.org/10.1159/000438708

Butler, M. G. (2017). Clinical and genetic aspects of the 15q11.2 BP1-BP2 microdeletion disorder. Journal of Intellectual Disability Research: JIDR, 61(6), 568-579. https://doi.org/10.1111/jir.12382

Ciani, L., Patel, A., Allen, N. D., \& ffrench-Constant, C. (2003). Mice lacking the giant protocadherin mFAT1 exhibit renal slit junction abnormalities and a partially penetrant cyclopia and anophthalmia phenotype. Molecular and Cellular Biology, 23(10), 3575-3582.

Cohen, M. M. (2006). Holoprosencephaly: clinical, anatomic, and molecular dimensions. Birth Defects Research. Part A, Clinical and Molecular Teratology, 76(9), 658-673.

https://doi.org/10.1002/bdra.20295

David, A., Liu, F., Tibelius, A., Vulprecht, J., Wald, D., Rothermel, U., ... Krämer, A. (2014). Lack of centrioles and primary cilia in STIL(-/-) mouse embryos. Cell Cycle (Georgetown, Tex.), 13(18), 2859-2868. https://doi.org/10.4161/15384101.2014.946830

de la Cruz, J. M., Bamford, R. N., Burdine, R. D., Roessler, E., Barkovich, A. J., Donnai, D., ... Muenke, M. (2002). A loss-of-function mutation in the CFC domain of TDGF1 is associated with human forebrain defects. Human Genetics, 110(5), 422-428. https://doi.org/10.1007/s00439-0020709-3

Démurger, F., Pasquier, L., Dubourg, C., Dupé, V., Gicquel, I., Evain, C., ... David, V. (2013). ArrayCGH Analysis Suggests Genetic Heterogeneity in Rhombencephalosynapsis. Molecular Syndromology, 4(6), 267-272. https://doi.org/10.1159/000353878

Dhamija, R., Kirmani, S., Wang, X., Ferber, M. J., Wieben, E. D., Lazaridis, K. N., \& BabovicVuksanovic, D. (2014). Novel de novo heterozygous FGFR1 mutation in two siblings with Hartsfield syndrome: a case of gonadal mosaicism. American Journal of Medical Genetics. Part A, 164A(9), 2356-2359. https://doi.org/10.1002/ajmg.a.36621

Dubourg, C., Bendavid, C., Pasquier, L., Henry, C., Odent, S., \& David, V. (2007). Holoprosencephaly. Orphanet Journal of Rare Diseases, 2, 8. https://doi.org/10.1186/1750-1172-2-8

Dubourg, C., Carré, W., Hamdi-Rozé, H., Mouden, C., Roume, J., Abdelmajid, B., ... David, V. (2016). Mutational Spectrum in Holoprosencephaly Shows That FGF is a New Major Signaling Pathway. Human Mutation, 37(12), 1329-1339. https://doi.org/10.1002/humu.23038

Dupé, V., Rochard, L., Mercier, S., Le Pétillon, Y., Gicquel, I., Bendavid, C., ... David, V. (2011). $\mathrm{NOTCH}$, a new signaling pathway implicated in holoprosencephaly. Human Molecular Genetics, 20(6), 1122-1131. https://doi.org/10.1093/hmg/ddq556

El-Jaick, K. B., Powers, S. E., Bartholin, L., Myers, K. R., Hahn, J., Orioli, I. M., ... Muenke, M. 
(2007). Functional analysis of mutations in TGIF associated with holoprosencephaly. Molecular Genetics and Metabolism, 90(1), 97-111. https://doi.org/10.1016/j.ymgme.2006.07.011

Fernandez, B. A., Roberts, W., Chung, B., Weksberg, R., Meyn, S., Szatmari, P., ... Scherer, S. W. (2010). Phenotypic spectrum associated with de novo and inherited deletions and duplications at $16 \mathrm{p} 11.2$ in individuals ascertained for diagnosis of autism spectrum disorder. Journal of Medical Genetics, 47(3), 195-203. https://doi.org/10.1136/jmg.2009.069369

Geng, X., \& Oliver, G. (2009). Pathogenesis of holoprosencephaly. The Journal of Clinical Investigation, 119(6), 1403-1413. https://doi.org/10.1172/JCI38937

Grobe, K. (2005). Cerebral hypoplasia and craniofacial defects in mice lacking heparan sulfate Ndst1 gene function. Development, 132(16), 3777-3786. https://doi.org/10.1242/dev.01935

Hahn, J. S., Barnes, P. D., Clegg, N. J., \& Stashinko, E. E. (2010). Septopreoptic holoprosencephaly: a mild subtype associated with midline craniofacial anomalies. AJNR. American Journal of

Neuroradiology, 31(9), 1596-1601. https://doi.org/10.3174/ajnr.A2123

Hong, M., Srivastava, K., Kim, S., Allen, B. L., Leahy, D. J., Hu, P., ... Muenke, M. (2017). BOC is a modifier gene in holoprosencephaly. Human Mutation, 38(11), 1464-1470.

https://doi.org/10.1002/humu.23286

Hong, S., Hu, P., Marino, J., Hufnagel, S. B., Hopkin, R. J., Toromanović, A., .. Muenke, M. (2016). Dominant-negative kinase domain mutations in FGFR1 can explain the clinical severity of Hartsfield syndrome. Human Molecular Genetics, 25(10), 1912-1922. https://doi.org/10.1093/hmg/ddw064

Hong, S., Hu, P., Roessler, E., Hu, T., \& Muenke, M. (2018). Loss-of-function mutations in FGF8 can be independent risk factors for holoprosencephaly. Human Molecular Genetics.

https://doi.org/10.1093/hmg/ddy106

Jean, D., Bernier, G., \& Gruss, P. (1999). Six6 (Optx2) is a novel murine Six3-related homeobox gene that demarcates the presumptive pituitary/hypothalamic axis and the ventral optic stalk. Mechanisms of Development, 84(1-2), 31-40.

Jin, O., Harpal, K., Ang, S. L., \& Rossant, J. (2001). Otx2 and HNF3beta genetically interact in anterior patterning. The International Journal of Developmental Biology, 45(1), 357-365.

Kakar, N., Ahmad, J., Morris-Rosendahl, D. J., Altmüller, J., Friedrich, K., Barbi, G., .. Borck, G. (2015). STIL mutation causes autosomal recessive microcephalic lobar holoprosencephaly. Human Genetics, 134(1), 45-51. https://doi.org/10.1007/s00439-014-1487-4

Karkera, J. D., Izraeli, S., Roessler, E., Dutra, A., Kirsch, I., \& Muenke, M. (2002). The genomic structure, chromosomal localization, and analysis of SIL as a candidate gene for holoprosencephaly. Cytogenetic and Genome Research, 97(1-2), 62-67. https://doi.org/10.1159/000064057

Krauss, R. S. (2007). Holoprosencephaly: new models, new insights. Expert Reviews in Molecular Medicine, 9(26), 1-17. https://doi.org/10.1017/S1462399407000440

Kruszka, P., Hart, R. A., Hadley, D. W., Muenke, M., \& Habal, M. B. (2015). Expanding the phenotypic expression of Sonic Hedgehog mutations beyond holoprosencephaly. The Journal of Craniofacial Surgery, 26(1), 3-5. https://doi.org/10.1097/SCS.0000000000001377 
Lacbawan, F., Solomon, B. D., Roessler, E., El-Jaick, K., Domené, S., Vélez, J. I., .. Muenke, M. (2009). Clinical spectrum of SIX3-associated mutations in holoprosencephaly: correlation between genotype, phenotype and function. Journal of Medical Genetics, 46(6), 389-398.

https://doi.org/10.1136/jmg.2008.063818

Lenglet, H., Schmitt, C., Grange, T., Manceau, H., Karboul, N., Bouchet-Crivat, F., ... Gouya, L. (2018). From a dominant to an oligogenic model of inheritance with environmental modifiers in acute intermittent porphyria. Human Molecular Genetics, 27(7), 1164-1173.

https://doi.org/10.1093/hmg/ddy030

Maione, L., Dwyer, A. A., Francou, B., Guiochon-Mantel, A., Binart, N., Bouligand, J., \& Young, J. (2018). GENETICS IN ENDOCRINOLOGY: Genetic counseling for congenital hypogonadotropic hypogonadism and Kallmann syndrome: new challenges in the era of oligogenism and next-generation sequencing. European Journal of Endocrinology, 178(3), R55-R80. https://doi.org/10.1530/EJE-170749

McCabe, M. J., Gaston-Massuet, C., Tziaferi, V., Gregory, L. C., Alatzoglou, K. S., Signore, M., ... Dattani, M. T. (2011). Novel FGF8 mutations associated with recessive holoprosencephaly, craniofacial defects, and hypothalamo-pituitary dysfunction. The Journal of Clinical Endocrinology and Metabolism, 96(10), E1709-1718. https://doi.org/10.1210/jc.2011-0454

Mencarelli, M. A., Heidet, L., Storey, H., van Geel, M., Knebelmann, B., Fallerini, C., ... Renieri, A. (2015). Evidence of digenic inheritance in Alport syndrome. Journal of Medical Genetics, 52(3), 163174. https://doi.org/10.1136/jmedgenet-2014-102822

Mercier, S., Dubourg, C., Garcelon, N., Campillo-Gimenez, B., Gicquel, I., Belleguic, M., ... Odent, S. (2011). New findings for phenotype-genotype correlations in a large European series of holoprosencephaly cases. Journal of Medical Genetics, 48(11), 752-760.

https://doi.org/10.1136/jmedgenet-2011-100339

M'hamdi, O., Redin, C., Stoetzel, C., Ouertani, I., Chaabouni, M., Maazoul, F., ... Chaabouni, H. (2014). Clinical and genetic characterization of Bardet-Biedl syndrome in Tunisia: defining a strategy for molecular diagnosis. Clinical Genetics, 85(2), 172-177. https://doi.org/10.1111/cge.12129

Ming, J. E., Kaupas, M. E., Roessler, E., Brunner, H. G., Golabi, M., Tekin, M., ... Muenke, M. (2002). Mutations in PATCHED-1, the receptor for SONIC HEDGEHOG, are associated with holoprosencephaly. Human Genetics, 110(4), 297-301. https://doi.org/10.1007/s00439-002-0695-5

Ming, J. E., \& Muenke, M. (2002). Multiple hits during early embryonic development: digenic diseases and holoprosencephaly. American Journal of Human Genetics, 71(5), 1017-1032. https://doi.org/10.1086/344412

Mouden, C., Dubourg, C., Carré, W., Rose, S., Quelin, C., Akloul, L., ... David, V. (2016). Complex mode of inheritance in holoprosencephaly revealed by whole exome sequencing. Clinical Genetics, 89(6), 659-668. https://doi.org/10.1111/cge.12722

Mouden, Charlotte, Tayrac, M. de, Dubourg, C., Rose, S., Carré, W., Hamdi-Rozé, H., ... David, V. (2015). Homozygous STIL Mutation Causes Holoprosencephaly and Microcephaly in Two Siblings. PLOS ONE, 10(2), e0117418. https://doi.org/10.1371/journal.pone.0117418

Muenke, M., \& Beachy, P. A. (2000). Genetics of ventral forebrain development and 
holoprosencephaly. Current Opinion in Genetics \& Development, 10(3), 262-269.

Nanni, L., Ming, J. E., Bocian, M., Steinhaus, K., Bianchi, D. W., Die-Smulders, C., ... Muenke, M. (1999). The mutational spectrum of the sonic hedgehog gene in holoprosencephaly: SHH mutations cause a significant proportion of autosomal dominant holoprosencephaly. Human Molecular Genetics, 8(13), 2479-2488.

Nguyen, H. P., Van Broeckhoven, C., \& van der Zee, J. (2018). ALS Genes in the Genomic Era and their Implications for FTD. Trends in Genetics: TIG. https://doi.org/10.1016/j.tig.2018.03.001

Odent, S., Le Marec, B., Munnich, A., Le Merrer, M., \& Bonaïti-Pellié, C. (1998). Segregation analysis in nonsyndromic holoprosencephaly. American Journal of Medical Genetics, 77(2), 139-143.

Pineda-Alvarez, D. E., Roessler, E., Hu, P., Srivastava, K., Solomon, B. D., Siple, C. E., ... Muenke, M. (2012). Missense substitutions in the GAS1 protein present in holoprosencephaly patients reduce the affinity for its ligand, SHH. Human Genetics, 131(2), 301-310. https://doi.org/10.1007/s00439011-1078-6

Ratié, L., Ware, M., Barloy-Hubler, F., Romé, H., Gicquel, I., Dubourg, C., ... Dupé, V. (2013). Novel genes upregulated when NOTCH signalling is disrupted during hypothalamic development. Neural Development, 8, 25. https://doi.org/10.1186/1749-8104-8-25

Reiter, J. F., \& Leroux, M. R. (2017). Genes and molecular pathways underpinning ciliopathies. Nature Reviews. Molecular Cell Biology, 18(9), 533-547. https://doi.org/10.1038/nrm.2017.60

Roessler, E., Belloni, E., Gaudenz, K., Jay, P., Berta, P., Scherer, S. W., .. Muenke, M. (1996). Mutations in the human Sonic Hedgehog gene cause holoprosencephaly. Nature Genetics, 14(3), 357360. https://doi.org/10.1038/ng1196-357

Roessler, Erich, Du, Y.-Z., Mullor, J. L., Casas, E., Allen, W. P., Gillessen-Kaesbach, G., ... Muenke, M. (2003). Loss-of-function mutations in the human GLI2 gene are associated with pituitary anomalies and holoprosencephaly-like features. Proceedings of the National Academy of Sciences of the United States of America, 100(23), 13424-13429. https://doi.org/10.1073/pnas.2235734100

Roessler, Erich, El-Jaick, K. B., Dubourg, C., Vélez, J. I., Solomon, B. D., Pineda-Alvarez, D. E., ... Muenke, M. (2009). The mutational spectrum of holoprosencephaly-associated changes within the SHH gene in humans predicts loss-of-function through either key structural alterations of the ligand or its altered synthesis. Human Mutation, 30(10), E921-935. https://doi.org/10.1002/humu.21090

Roessler, Erich, Lacbawan, F., Dubourg, C., Paulussen, A., Herbergs, J., Hehr, U., ... Muenke, M. (2009). The full spectrum of holoprosencephaly-associated mutations within the ZIC2 gene in humans predicts loss-of-function as the predominant disease mechanism. Human Mutation, 30(4), E541-554. https://doi.org/10.1002/humu.20982

Roessler, Erich, Ma, Y., Ouspenskaia, M. V., Lacbawan, F., Bendavid, C., Dubourg, C., ... Muenke, M. (2009). Truncating loss-of-function mutations of DISP1 contribute to holoprosencephaly-like microform features in humans. Human Genetics, 125(4), 393-400. https://doi.org/10.1007/s00439009-0628-7

Roessler, Erich, Ouspenskaia, M. V., Karkera, J. D., Vélez, J. I., Kantipong, A., Lacbawan, F., ... Muenke, M. (2008). Reduced NODAL signaling strength via mutation of several pathway members including FOXH1 is linked to human heart defects and holoprosencephaly. American Journal of 
Roessler, Erich, Pei, W., Ouspenskaia, M. V., Karkera, J. D., Veléz, J. I., Banerjee-Basu, S., ... Muenke, M. (2009). Cumulative ligand activity of NODAL mutations and modifiers are linked to human heart defects and holoprosencephaly. Molecular Genetics and Metabolism, 98(1-2), 225-234. https://doi.org/10.1016/j.ymgme.2009.05.005

Roessler, Erich, Vélez, J. I., Zhou, N., \& Muenke, M. (2012). Utilizing prospective sequence analysis of SHH, ZIC2, SIX3 and TGIF in holoprosencephaly probands to describe the parameters limiting the observed frequency of mutant gene× gene interactions. Molecular Genetics and Metabolism, 105(4), 658-664. https://doi.org/10.1016/j.ymgme.2012.01.005

Rosenfeld, J. A., Ballif, B. C., Martin, D. M., Aylsworth, A. S., Bejjani, B. A., Torchia, B. S., \& Shaffer, L. G. (2010). Clinical characterization of individuals with deletions of genes in holoprosencephaly pathways by aCGH refines the phenotypic spectrum of HPE. Human Genetics, 127(4), 421-440. https://doi.org/10.1007/s00439-009-0778-7

Ruiz i Altaba, A., Palma, V., \& Dahmane, N. (2002). Hedgehog-Gli signalling and the growth of the brain. Nature Reviews. Neuroscience, 3(1), 24-33. https://doi.org/10.1038/nrn704

Schachter, K. A., \& Krauss, R. S. (2008). Murine models of holoprosencephaly. Current Topics in Developmental Biology, 84, 139-170. https://doi.org/10.1016/S0070-2153(08)00603-0

Simonis, N., Migeotte, I., Lambert, N., Perazzolo, C., de Silva, D. C., Dimitrov, B., ... Vilain, C. (2013). FGFR1 mutations cause Hartsfield syndrome, the unique association of holoprosencephaly and ectrodactyly. Journal of Medical Genetics, 50(9), 585-592. https://doi.org/10.1136/jmedgenet2013-101603

Solomon, B. D., Bear, K. A., Wyllie, A., Keaton, A. A., Dubourg, C., David, V., ... Muenke, M. (2012). Genotypic and phenotypic analysis of 396 individuals with mutations in Sonic Hedgehog. Journal of Medical Genetics, 49(7), 473-479. https://doi.org/10.1136/jmedgenet-2012-101008

Solomon, B. D., Mercier, S., Vélez, J. I., Pineda-Alvarez, D. E., Wyllie, A., Zhou, N., ... Muenke, M. (2010). Analysis of genotype-phenotype correlations in human holoprosencephaly. American Journal of Medical Genetics. Part C, Seminars in Medical Genetics, 154C(1), 133-141.

https://doi.org/10.1002/ajmg.c.30240

Stokes, B., Berger, S. I., Hall, B. A., Weiss, K., Martinez, A. F., Hadley, D. W., ... Muenke, M. (2018). SIX3 deletions and incomplete penetrance in families affected by holoprosencephaly. Congenital Anomalies, 58(1), 29-32. https://doi.org/10.1111/cga.12234

Storm, E. E., Garel, S., Borello, U., Hebert, J. M., Martinez, S., McConnell, S. K., ... Rubenstein, J. L. R. (2006). Dose-dependent functions of Fgf8 in regulating telencephalic patterning centers. Development (Cambridge, England), 133(9), 1831-1844. https://doi.org/10.1242/dev.02324

Sun, L., Carr, A. L., Li, P., Lee, J., McGregor, M., \& Li, L. (2014). Characterization of the human oncogene SCL/TAL1 interrupting locus (Stil) mediated Sonic hedgehog (Shh) signaling transduction in proliferating mammalian dopaminergic neurons. Biochemical and Biophysical Research Communications, 449(4), 444-448. https://doi.org/10.1016/j.bbrc.2014.05.048

Sun, X., Meyers, E. N., Lewandoski, M., \& Martin, G. R. (1999). Targeted disruption of Fgf8 causes failure of cell migration in the gastrulating mouse embryo. Genes \& Development, 13(14), 1834-1846. 
Tian, H., Jeong, J., Harfe, B. D., Tabin, C. J., \& McMahon, A. P. (2005). Mouse Disp1 is required in sonic hedgehog-expressing cells for paracrine activity of the cholesterol-modified ligand. Development (Cambridge, England), 132(1), 133-142. https://doi.org/10.1242/dev.01563

Ware, M., Hamdi-Rozé, H., \& Dupé, V. (2014). Notch signaling and proneural genes work together to control the neural building blocks for the initial scaffold in the hypothalamus. Frontiers in Neuroanatomy, 8, 140. https://doi.org/10.3389/fnana.2014.00140

Xavier, G. M., Seppala, M., Barrell, W., Birjandi, A. A., Geoghegan, F., \& Cobourne, M. T. (2016). Hedgehog receptor function during craniofacial development. Developmental Biology, 415(2), 198 215. https://doi.org/10.1016/j.ydbio.2016.02.009

Yin, J., \& Schaaf, C. P. (2017). Autism genetics - an overview. Prenatal Diagnosis, 37(1), 14-30. https://doi.org/10.1002/pd.4942

\section{Figure legends}

Figure 1. Clinical and molecular details of the European HPE cohort

(A) Brain anomalies distribution in European HPE cohort (1,420 probands).

(B) Mutational spectrum of HPE.

In blue, number of variants found in 2010. 164/642 (25.4\%) patients were found to harbor variants in SHH, ZIC2, SIX3 or TGIF1. GLI2 variants were identified in 3/208 patients (Mercier et al., 2011). In red, number of variants found in 2017. Molecular screening of major HPE genes in 1,420 patients revealed 207 variants in SHH, ZIC2, SIX3 and TGIF1. Complementary screenings on a series of 302 patients revealed 32 variants in DLL1, FGF8, FGFR1, DISP1 and GLI2.

(C) Contribution of CGH-array to molecular diagnosis. In 2010, CNVs were detected in $22 \%$ of the 260 patients analyzed by CGH-array, including 36 occurring de novo. In 2017, the screening of our entire cohort (1,420 patients) reported CNVs in 142 patients (10\%), including 71 occurring de novo.

Figure 2. Examples of complex inheritance in HPE.

(A) Family presenting a digenic mode of transmission associating variants in SHH and DISP1 (Mouden et al., 2016). Minor signs refer to microcephaly.

(B) Family presenting an oligogenic pattern with combined inherited variants in SHH, FAT1 and NDST1. Minor signs refer to hypotelorism (father) and epicanthus (mother).

Individuals marked with asterisk were analyzed by whole exome sequencing. NA: Not available for $D I S P 1$ sequencing. 
Figure 3. Different inheritance patterns for HPE are presented together with illustrative cases from our unpublished data. 
TABLE I. List of HPE genes and corresponding percentages of variants found in our HPE cohort.

\begin{tabular}{|c|c|c|c|}
\hline Chromosome & Gene & NM & $\%$ \\
7 & SHH & 000193.2 & 5.4 \\
13 & ZIC2 & 007129.3 & 5.2 \\
2 & GLI2 & 005270.4 & 3.2 \\
2 & SIX3 & 005413.3 & 3.0 \\
10 & FGF8 & 033163.3 & 2.5 \\
8 & FGFR1 & 023110.2 & 2.0 \\
1 & DISP1 & 032890.3 & 1.2 \\
6 & DLL1 & 005618.3 & 1.2 \\
18 & TGIF1 & 170695.2 & 0.9 \\
10 & SUFU & 016169.3 & 0.4 \\
1 & STIL & 001048166.1 & 1 case/375 \\
9 & GAS1 & 002048.2 & 0 \\
3 & TDGF1 & 003212.3 & 0 \\
11 & CDON & 016952.4 & 0 \\
8 & FOXH1 & 003923.2 & 0 \\
10 & NODAL & 018055.4 & 0 \\
3 & BOC & 001301861.1 & Not tested \\
\hline
\end{tabular}


TABLE II: Summary of chromosomal abnormalities in HPE cases

\begin{tabular}{|c|c|c|c|c|c|}
\hline Patient & Cytoband & Type of CNV & $\begin{array}{l}\text { Start-End } \\
\text { (GRCh37) }\end{array}$ & CNV size & Inheritance \\
\hline 1 & $\begin{array}{l}1 q 43 q 44 \\
3 p 25.2 p 22.1\end{array}$ & $\begin{array}{l}\text { del } \\
\text { dup }\end{array}$ & $\begin{array}{l}242094954 \\
249212668 \\
0_{-} \\
39848444\end{array}$ & $\begin{array}{l}7 \mathrm{Mb} \\
40 \mathrm{Mb}\end{array}$ & $\begin{array}{l}\text { Inherited from } \\
\text { parental balanced } \\
t(1 ; 3)\end{array}$ \\
\hline 2 & $2 \mathrm{p} 15$ & del & $\begin{array}{l}61668439 \\
61777447\end{array}$ & $109 \mathrm{~kb}$ & De novo \\
\hline 3 & $\begin{array}{l}\text { 2p11.2 } \\
\text { 16p13.11* }\end{array}$ & $\begin{array}{l}\text { dup } \\
\text { dup }\end{array}$ & $\begin{array}{l}85824180 \\
86469217 \\
15492317 \\
16276115\end{array}$ & $\begin{array}{l}645 \mathrm{~kb} \\
784 \mathrm{~kb}\end{array}$ & $\begin{array}{l}\text { De novo } \\
\text { Inherited from father }\end{array}$ \\
\hline 4 & $3 p 22 ; 20 q 11.2$ & $\begin{array}{l}\text { balanced } \\
\text { translocation }\end{array}$ & - & - & Inherited from mother \\
\hline 5 & $3 q 25.32$ & del & $\begin{array}{l}157105931 \\
157154842\end{array}$ & $50 \mathrm{~kb}$ & Inherited from mother \\
\hline 6 & $4 q 12$ & del & $\begin{array}{l}55193357 \\
58196685\end{array}$ & $3,00 \mathrm{Mb}$ & ND \\
\hline 7 & $5 q 35.3$ & del & $\begin{array}{l}177296851 \\
178323802\end{array}$ & $1 \mathrm{Mb}$ & Inherited from mother \\
\hline 8 & $5 q 35.3$ & dup & $\begin{array}{l}178038828- \\
179766520\end{array}$ & $1,73 \mathrm{Mb}$ & Inherited \\
\hline 9 & $7 p 22.1$ & del & $\begin{array}{l}5399371 \\
6871084\end{array}$ & $1,4 \mathrm{Mb}$ & De novo \\
\hline 10 & $7 p 22.1$ & dup & $\begin{array}{l}5057686 \\
5166175\end{array}$ & $108 \mathrm{~kb}$ & Inherited from father \\
\hline 11 & $8 q 23.3 q 24.11$ & del & $\begin{array}{l}117641330- \\
118051191\end{array}$ & $410 \mathrm{~kb}$ & ND \\
\hline 12 & Whole chromosome 8 & dup in mosaic & $\begin{array}{l}0_{-} \\
146294098\end{array}$ & $146 \mathrm{Mb}$ & De novo \\
\hline 13 & 10p15.3p14 & del & $136361-9946915$ & $9,8 \mathrm{Mb}$ & De novo \\
\hline 14 & $11 q 13.4$ & dup & $\begin{array}{l}74931870- \\
75109882\end{array}$ & $178 \mathrm{~kb}$ & Inherited from mother \\
\hline 15 & $12 q 21.32$ & del & $\begin{array}{l}86984993 \\
87656628\end{array}$ & $672 \mathrm{~kb}$ & ND \\
\hline 16 & $14 q 23.1$ & del & $\begin{array}{l}60950490_{-} \\
61006021\end{array}$ & $55 \mathrm{~kb}$ & Inherited from mother \\
\hline 17 & $14 q 23.1$ & dup & Unavailable data & $900 \mathrm{~kb}$ & Inherited from mother \\
\hline 18 & $15 q 11.2^{*}$ & del & $\begin{array}{l}22765628- \\
23208901 \\
\end{array}$ & $443 \mathrm{~kb}$ & Inherited from mother \\
\hline 19 & $\begin{array}{l}\text { 16p13.11* } \\
16 p 11.2^{*}\end{array}$ & $\begin{array}{l}\text { del } \\
\text { dup }\end{array}$ & $\begin{array}{l}15492317 \\
16267306 \\
29652999 \\
30197341\end{array}$ & $\begin{array}{l}1,3 \mathrm{Mb} \\
544 \mathrm{~kb}\end{array}$ & $\begin{array}{l}\text { ND } \\
\text { Inherited from mother }\end{array}$ \\
\hline 20 & $18 q 22.1$ & dup & $\begin{array}{l}64152648 \\
64324336\end{array}$ & $172 \mathrm{~kb}$ & Inherited from mother \\
\hline 21 & $19 q 13.42 q 13.43$ & dup & $\begin{array}{l}56228025 \\
57744093\end{array}$ & $1,5 \mathrm{Mb}$ & De novo \\
\hline 22 & $22 q 11.21^{*}$ & del & $\begin{array}{l}\text { 20719112- } \\
21464119\end{array}$ & $745 \mathrm{~kb}$ & ND \\
\hline 23 & $22 q 11.21^{*}$ & del & $\begin{array}{l}21081060 \\
21505558\end{array}$ & $424 \mathrm{~kb}$ & De novo \\
\hline 24 & $22 q 11.21^{*}$ & del & $\begin{array}{l}18894835 \\
21464119\end{array}$ & $2,6 \mathrm{Mb}$ & De novo \\
\hline 25 & $22 q 11.21^{*}$ & del & $\begin{array}{l}18894835 \\
21464119\end{array}$ & $2,6 \mathrm{Mb}$ & De novo \\
\hline 26 & $22 q 11.21^{*}$ & del & $\begin{array}{l}18651614 \\
21801661\end{array}$ & $3,2 \mathrm{Mb}$ & ND \\
\hline 27 & Xq25q28 & del & $\begin{array}{l}123176394- \\
152515593\end{array}$ & $29,34 \mathrm{Mb}$ & De novo \\
\hline
\end{tabular}

del = deletion; dup = duplication; ND = not determined; *CNV (Copy number variation) usually observed in intellectual deficiency 
A Distribution of brain anomalies in European HPE cohort

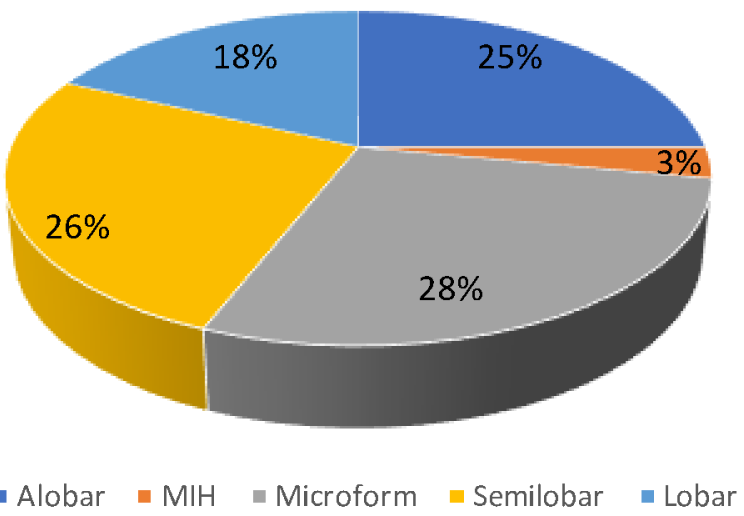

B

Number of mutations in HPE genes 2010 / 2017

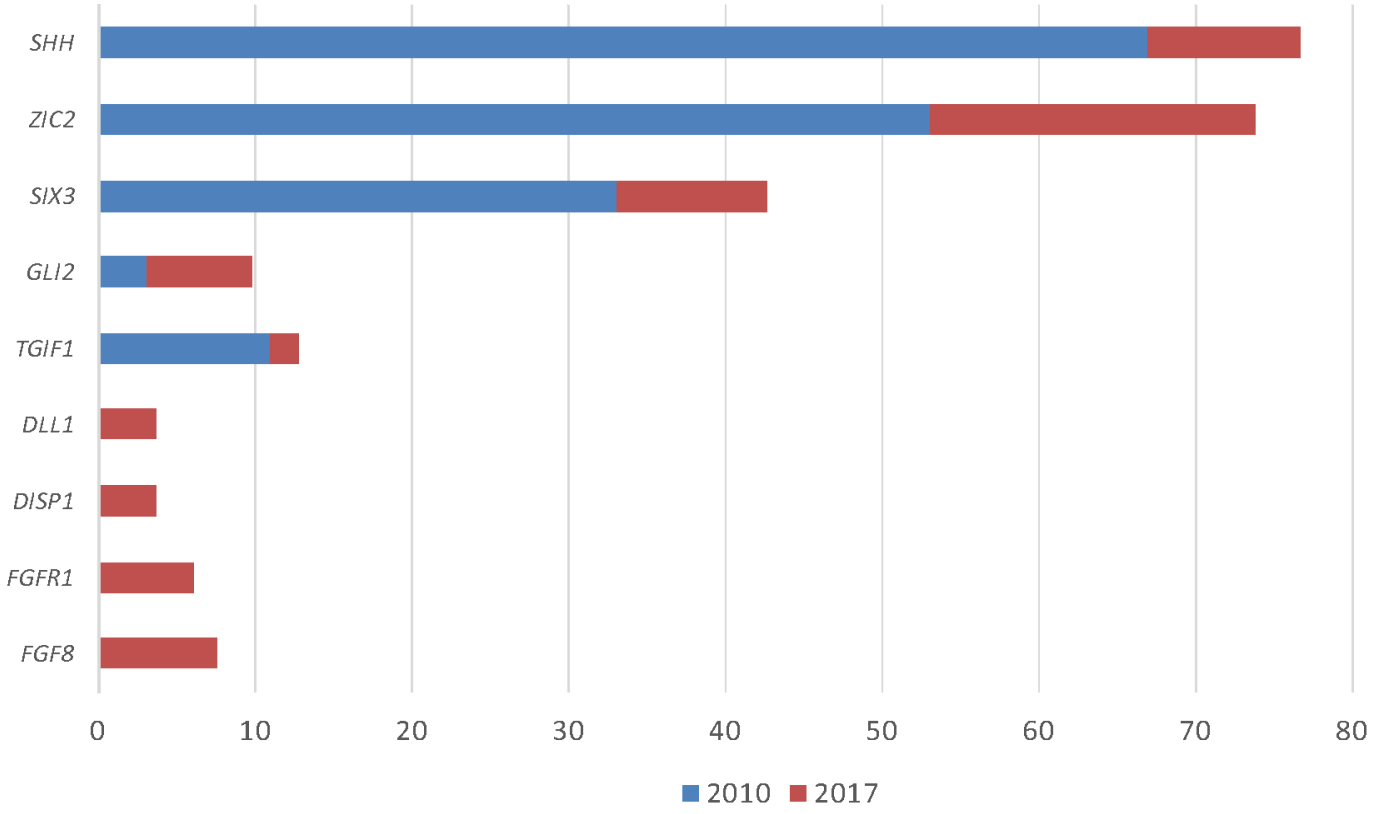

C

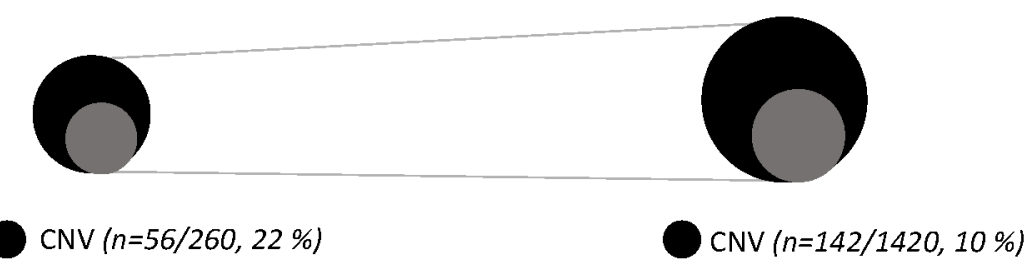

De novo CNV $(n=36)$

De novo $\operatorname{CNV}(n=71)$

2017 


\section{Page 25 of 26}

Wiley-Phase 1

A

B

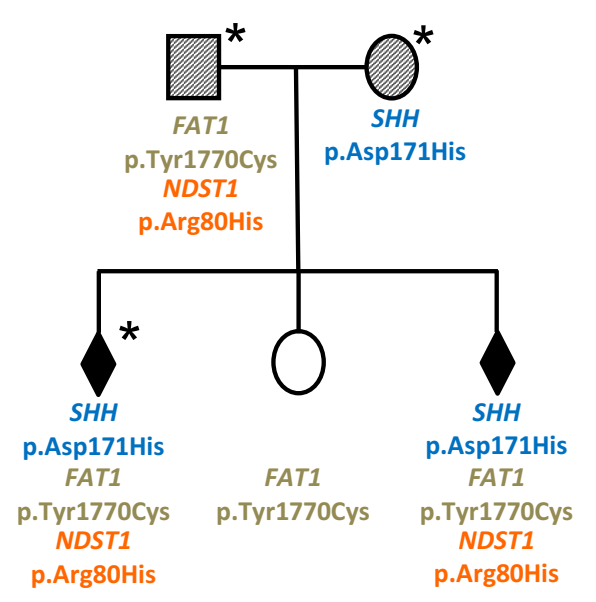

Severe HPE minor signs or microform HPE 
Autosomal dominant (de novo)

$$
\sim 35 \%
$$

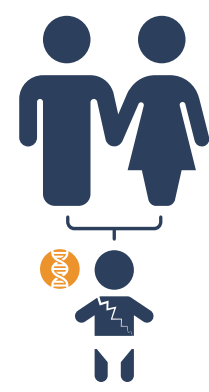

ZIC2 (70\%)

FGFR1 (50\%)

$\mathrm{SHH}(30 \%)$

SIX3 (30\%)
Autosomal recessive

$$
<1 \%
$$

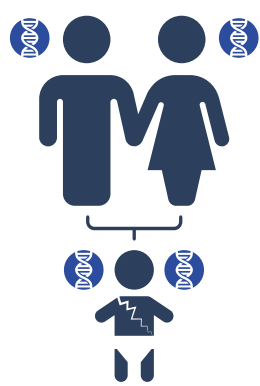

STIL/STIL

DISP1/DISP1

TGIF1/TGIF1

FGF8/FGF8

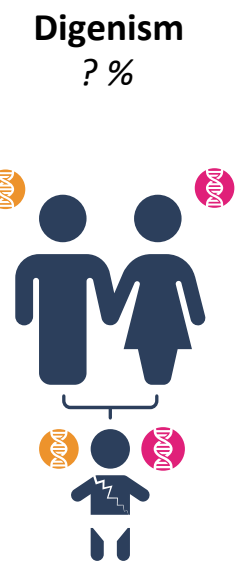

SHH/DISP1

SIX3/PTCH1

SHH/DLL1

FGF8/FGFR1
Oligogenism

? \%

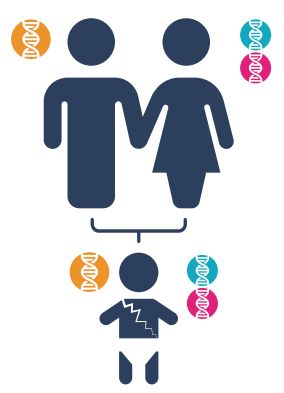

SHH/FAT1/NDST1 